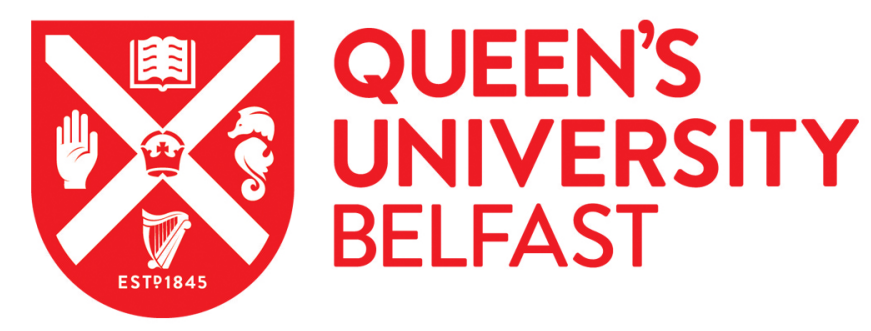

\title{
Validating clinical practice guidelines for the management of children with non-blanching rashes in the UK (PiC) a prospective, multicentre cohort study
}

Paediatric Emergency Research in the UK and Ireland (PERUKI) Group (2021). Validating clinical practice guidelines for the management of children with non-blanching rashes in the UK (PiC) a prospective, multicentre cohort study. The Lancet Infectious Diseases, 21(4), 569-577. https://doi.org/10.1016/S1473-3099(20)30474-6

Published in:

The Lancet Infectious Diseases

Document Version:

Peer reviewed version

Queen's University Belfast - Research Portal:

Link to publication record in Queen's University Belfast Research Portal

\section{Publisher rights}

Copyright 2020 Elsevier.

This manuscript is distributed under a Creative Commons Attribution-NonCommercial-NoDerivs License

(https://creativecommons.org/licenses/by-nc-nd/4.0/), which permits distribution and reproduction for non-commercial purposes, provided the author and source are cited.

\section{General rights}

Copyright for the publications made accessible via the Queen's University Belfast Research Portal is retained by the author(s) and / or other copyright owners and it is a condition of accessing these publications that users recognise and abide by the legal requirements associated with these rights.

\section{Take down policy}

The Research Portal is Queen's institutional repository that provides access to Queen's research output. Every effort has been made to ensure that content in the Research Portal does not infringe any person's rights, or applicable UK laws. If you discover content in the

Research Portal that you believe breaches copyright or violates any law, please contact openaccess@qub.ac.uk. 


\section{Validating clinical practice guidelines for the management of children with non- blanching rashes in the United Kingdom.}

Author list \& institutions

1. Thomas Waterfield (BMBCh)

- Emergency Department, Royal Belfast Hospital for Sick Children, Belfast, UK

- Centre for Experimental Medicine, Wellcome Wolfson Institute of Experimental Medicine, Queen's University Belfast, Belfast, UK

2. Julie-Ann Maney (MBBCh)

- Emergency Department, Royal Belfast Hospital for Sick Children, Belfast, UK

3. Derek Fairley $(\mathrm{PhD})$

- Department of Microbiology, Belfast Health and Social Care Trust, Belfast, UK

- Centre for Experimental Medicine, Wellcome Wolfson Institute of

4. Mark D Lyttle (MBChB) Experimental Medicine, Queen's University Belfast, Belfast, UK

- Emergency Department, Bristol Royal Hospital for Children, Bristol, UK

- Faculty of Health and Applied Sciences, University of the West of England, Bristol, UK

5. James P McKenna (PhD)

- Department of Microbiology, Belfast Health and Social Care Trust, Belfast, UK

6. Damian Roland (PhD)

- $\quad$ SAPPHIRE Group, Health Sciences, Leicester University, Leicester, UK

- Children's Emergency Department, Leicester Royal Infirmary, Leicester, UK

7. Michael Corr (MBBCh)

- Belfast Health and Social Care Trust, Belfast, UK

8. Lisa McFetridge (PhD)

- Mathematical Sciences Research Centre, Queen's University Belfast, Belfast, UK

9. Hannah Mitchell (PhD)

- Mathematical Sciences Research Centre, Queen's University Belfast, Belfast, UK

10. Kerry Woolfall (PhD)

- Institute of Population Health and Society, The University of Liverpool, Liverpool, UK

11. Fiona Lynn (PhD)

- School of Nursing and Midwifery, Centre for Evidence and Social Innovation, Queen's University Belfast, Belfast, UK

12. Bethany Patenall (MSc)

- Department of Chemistry ,University of Bath, Bath, UK

13. Michael D Shields (MD)

- Centre for Experimental Medicine, Wellcome Wolfson Institute of Experimental Medicine, Queen's University Belfast, Belfast, UK

On behalf of Paediatric Emergency Research in the UK and Ireland (PERUKI)

Corresponding author - Thomas Waterfield, Centre for Experimental Medicine, Wellcome Wolfson Institute of Experimental Medicine, Queen's University Belfast, Belfast, UK

t.waterfield@qub.ac.uk

Phone: 07872990521 


\section{Abstract}

Background

The aim of this prospective cohort study was to report the performance of existing clinical practice guidelines (CPG) for diagnosis of invasive meningococcal disease (MD) in children presenting with fever and non-blanching rash in the UK.

\section{Methods}

Data were collected prospectively from 37 UK Emergency Departments (ED) between November 2017 and June 2019. Children under 18 years of age presenting with fever and non-blanching rash were included. Invasive meningococcal disease was confirmed by positive culture/quantitative PCR for $N$. meningitidis from either blood or cerebrospinal fluid.

\section{Findings}

A total of 1329 patients were included in the analysis. Median age was 24 months (interquartile range 12 to 48$), 1137(85 \cdot 6 \%)$ underwent blood testing, and 596(44.8\%) received parenteral antibiotics. There were 19 cases of MD (1.4\%). All CPGs $(n=8)$ demonstrated a sensitivity of 1.00 for the identification of MD. National Institute for Health and Care Excellence (NICE) guidelines CG102 and NG51 demonstrated specificities of 0.00 and 0.01 respectively for the identification of MD. The specificities of the NICE CPGs were significantly lower $(p<0.0001)$ than all other CPGs. The best performing CPGs were the London and Nottingham CPGs with specificities of 0.36 and 0.34 respectively for the identification of MD.

Interpretation

In the UK invasive meningococcal disease is now a rare cause of non-blanching rashes in children presenting to the ED. Current NICE guidance performs poorly when compared to alternative CPGs.

\section{Funding}

This study was funded by the Public Health Agency (EAT/5313/16). The funder had no involvement in the design or conduct of the study. 


\section{Background}

Despite successful vaccination programmes meningococcal disease (MD) remains one of the leading infectious causes of childhood septicaemia and death in the UK $(1,2,4)$. Early diagnosis may reduce morbidity and mortality $(1,2)$, but this is challenging when relying on clinical assessment and currently available tests $(1,4)$. MD presents with a number of phenotypes, but the most typically described is non-blanching rash (NBR) in the context of a feverish illness (1-4). However this constellation of clinical features represents a relatively common presentation to emergency departments (ED), and the vast majority of these children have a self-limiting viral illness (5-11). Differentiating feverish children with NBRs who have MD from those with a benign cause is difficult $(1,2)$. The resultant diagnostic dilemma for clinicians predisposes to a cautious approach, with many children undergoing painful procedures and receiving unnecessary broad-spectrum parenteral antibiotics. Despite this cautious approach early MD may still be missed, and children may be discharged home with adverse sequelae (11). Current clinical practice guidelines (CPG) are based on evidence which predates the introduction of meningococcal B and C vaccines. The quality of this underpinning evidence is also largely limited due to single centre or retrospective design, and use of convenience samples with small patient numbers (7-11). These historical studies reported MD as the causal pathogen in children with fever and NBR in $10-20 \%$ of cases (711). This reported high prevalence of $M D$ has led to the reasonable but aggressive investigation and treatment strategies suggested by some CPGs. Vaccination programmes have since reduced the prevalence of MD in many countries including the UK $(12,13)$, likely affecting the performance of CPGs, and creating a need for a well-powered validation study. The Petechiae in Children (PiC) study set out to prospectively assess management of children with fever and NBRs presenting to paediatric Emergency Departments (ED) in the UK (14). The study protocol was designed to observe current practice, validate existing CPGs, and report the accuracy of a range of diagnostic tests. The primary outcome of this validation study was to evaluate the performance accuracy of current UK CPGs for the diagnosis of MD in febrile children with a NBR. 


\section{Methods}

Study design

The protocol for the Petechiae in Children $(\mathrm{PiC})$ study has previously been published and adheres to the TRIPOD statement for prediction model validation (TRIPOD checklist in supplementary material) (14). This prospective multicentre cohort study was conducted at 37 UK paediatric Emergency Departments between the 9th of November 2017 and the 30th of June 2019 (recruitment summary available in Table 1)(15). Participating centres were distributed across the UK with one centre in Northern Ireland, three centres in Scotland and thirty-three centres in England, and included a range of tertiary paediatric specialist and district general hospitals. Children under 18 years of age attending, the EDs of, participating centres with reported or recorded fever $\left(\geq 38^{\circ} \mathrm{C}\right)$, and a new-onset NBR or features suggestive of meningococcal infection, were eligible for inclusion. Children with pre-existing haematological conditions (for example, haematological malignancy, idiopathic thrombocytopenic purpura (ITP), or coagulopathy) were excluded, as were children with an existing diagnosis of HenochSchonlein purpura (HSP).

\section{Outcome measures}

The primary outcome measure was the performance accuracy of CPGs at identifying children with invasive MD. Secondary outcome measures included diagnosis of other invasive bacterial infections and a cost comparison between the CPGs.

\section{Identifying clinical risk factors}

Potential clinical risk factors for MD were identified by reviewing CPGs from all participating sites, and included in the clinician case report form (CRF1; supplementary material). Eight CPGs were submitted prior to study commencement: Barts and the London [London CPG], Countess of Chester Hospital [Chester CPG], NICE Meningitis (bacterial) and meningococcal septicaemia in under 16s: recognition, diagnosis and management [NICE CG102], NICE 
Sepsis: recognition, diagnosis and early management [NICE NG51], Newcastle-BirminghamLiverpool [NBL CPG], Nottingham Children's Hospital [Nottingham CPG], Royal Hospital for Children Glasgow [Glasgow CPG] and the Bristol Royal Hospital for Children [Bristol CPG]. The CPGs are available in the supplementary material. The risk factors identified included background information (age, vaccination status), description and progression of rash, duration of illness, appearance of child, presence of signs of shock and meningism, gastrointestinal symptoms, other symptoms (e.g. reduced conscious level, respiratory symptoms, limb pain), and blood results.

\section{Study procedures}

Patients were screened for eligibility by clinical staff at the time of medical assessment, and study data were recorded prospectively using an electronic CRF (supplementary material). These data were recorded contemporaneously by clinical staff prior to consent discussions, and before laboratory test results were available. All participants in the PiC study received clinical care as per local guidance without delay.

\section{Reference standards}

The reference standard for identification of $\mathrm{MD}$ or other invasive bacterial infection (IBI) against which the performance of existing CPGs were assessed was defined as positive culture or PCR for N. meningitidis or other bacterial pathogen from a sterile body site (eg blood or CSF), performed by technicians blinded to clinical information at accredited National Health Service (NHS) hospital laboratories. Hospital records were subsequently checked for reattendance of participants who did not have culture/PCR testing, and these were assumed not to have MD provided the following criteria were met:

1) They were not subsequently diagnosed with MD within seven days of discharge

2) They did not have a MD notification to the public health agency 


\section{Consent model}

Due to the potentially life-threatening nature of invasive MD, research without prior consent (RWPC) was utlilised, and is described in full in the published study protocol $(14,16,17)$. Participants were enrolled to ensure contemporaneous data collection and were thereafter invited to provide consent at the earliest appropriate opportunity (typically within 24 hours) once the clinical condition had stabilised.

Identifying missed cases of $M D$.

At the close of the study, participating sites identified all children who had positive MD culture or PCR tests by checking notifications to the Public Health Agency. MD is a notifiable disease in the UK and this represents a reliable method for such an identification strategy. This list was cross-referenced with enrolled participants, and where patients with positive MD results were not enrolled, reasons for this were included. Research teams were also required to check for any unplanned re-attendances within seven days of discharge as a further mechanism to identify any participants with MD who may have been initially discharged without treatment.

\section{Data management}

Study data were collected and managed using REDCap (Research Electronic Data Capture) electronic data capture tools (18). The initial CRF was completed by treating clinicians to contemporaneously record data regarding the appearance of the patient at first medical assessment. The second CRF was completed seven days after discharge, and recorded laboratory results, length of stay, and other aspects of care not susceptible to recall bias. Any participants with incomplete data were excluded from the analysis (CRFs available in supplementary material). Prior to statistical analysis three authors (TW, LM, HM) checked the database for completeness of data using IBM statistical package for social sciences (SPSS) version 23. Two authors (TW and MDS) applied the eight CPGs to the data set. As standard care was followed, not all children underwent blood testing and so where this was the case, single imputation with data assumed to within the normal range i.e. CRP $<6 \mathrm{mg} / \mathrm{l}$, WCC 
between 5 x109 and $15 \times 109$, Neutrophils <10 x109 was undertaken. We selected this approach because none of the participants without blood testing received parenteral antibiotics and none of them were subsequently diagnosed with MD. The population without blood testing results were those at lowest risk of MD.

To minimise potential bias from this approach the analysis was repeated using two additional techniques. Firstly with missing data (CRP and WCC) imputed via multiple imputation with chained equations to create five imputed datasets and secondly with cases with incomplete test data (CRP and WCC) excluded.

\section{Data analysis}

The PiC study population were described in terms of demographic characteristics, vaccination status, risk factors, parenteral antibiotic use, admission to hospital, admission to intensive care units, and survival using descriptive statistics. The performance of the eight CPGs were compared using sensitivity, specificity, negative predictive value (NPV) and positive predictive value (PPV) (with 95\% confidence intervals). The McNemar's test was used to assess the significance of the difference in sensitivities and specificities between the eight CPG. The clinical risk factors assessed in a stepwise approach. Initially all possible predictors were assessed using univariate analysis with Chi-squared testing of categorical data, and the Mann-Whitney $U$ test for continuous data (continuous data were skewed). Age-dependent predictors such as heart rate, respiratory rate and blood pressure were converted to categorical data and classified as normal or abnormal based on published normal ranges [18]. All those predictors with a statistically significant association with $M D(p<0.20)$ were included in a binary multivariate logistic regression model. A liberal level of significance $(p<0.20)$ was chosen to avoid falsely excluding a significant variable based on univariate analysis alone. The predictors identified from the univariate analysis were then included in the logistic regression modelling. Empirical binary multivariate forward and backward logistic regression modeling was used to identify a best-fit model to identify children at highest risk of MD. 
Cost comparison

A decision analytic model was constructed to compare the costs of the different CPGs and clinician practice (supplementary material). The cost comparison analysis was conducted from the perspective of the NHS and included costs associated with hospital resource use for the diagnosis and inpatient care of study participants using a case-mix group approach. Data were identified and recorded seven days after discharge. Clinical pathways were detailed for three groups: those assessed in the ED and discharged, those assessed in the ED and admitted, and those assessed in the ED and admitted for treatment of MD. Resource use for each group was assessed and costed in UK Sterling (£) using unit costs from the National Schedule of Reference Costs 2017-2018 of NHS Trusts and Primary Care Trusts combined (19). Average costs per patient to the NHS were estimated. A Monte Carlo simulation method, bootstrapping, was used to replicate the sample with 10,000 iterations to estimate bootstrapped $95 \%$ confidence intervals around the mean cost per patient.

Public and patient involvement (PPI)

There has been public and patient involvement with the PiC study from outset. The PiC PPI group was convened specifically for this PiC study and included parents of children with a history of either meningococcal infection or a non-blanching rash. The PPI group contributed to the design of the PiC study, including the protocol, study information, and RWPC methodology. The PPI lead sat on the trial oversight committee and received regular updates regarding progress, and was a co-author on the published PiC protocol (14). Members of the PPI group promoted the study locally and nationally through appearances on local and national radio and television.

\section{Office for Research Ethics Committees (OREC) and local Research Governance}

The Northern Ireland OREC and the Belfast Health and Social Care Trust reviewed the PiC study protocol and provided a favourable outcome (Project ID 224660, OREC ID 17/NI/0169). 


\section{Study registration}

The $\mathrm{PiC}$ study was registered at https://www.clinicaltrials.gov (trial registration: NCT03378258) on the 19th of December 2017.

\section{Findings}

Between the 9th of November 2017 and the 30th of June 2019, 1513 consecutive patients were screened, of whom 179 were excluded; 149 did not fulfil eligibility criteria, 21 declined consent, eight could not provide consent due to a language barrier, and in one case it was unclear who had parental responsibility. The remaining 1334 children were enrolled, and 1329 were included in the analysis; five were excluded due to incomplete data (Figure 1). The recruitment by site can be visualised in Table 1.The median age of participants was 24 months (interquartile range 12 to 48 months), and 765 (58\%) were male. Most were up to date with age-appropriate vaccinations, with $926(70 \%)$ having received at least one dose of meningococcal B vaccine and $973(73 \%)$ having received at least one dose of meningococcal C vaccine (Table 2). A total of 1137 (86\%) underwent blood testing and 596 (45\%) received parenteral antibiotics. The median length of stay of hospitalised patients was one night (interquartile range 0 to 2). Eleven of the $1329(0 \cdot 8 \%)$ required admission to paediatric intensive care units (PICU) and two (0.2\%) died. There were $19(1.4 \%)$ confirmed cases of MD in the study population (17 group $B$, one group $C$ and one group $W$ ) and a further two confirmed MD cases were not enrolled. One was missed, and the other was not enrolled as local staff felt inclusion would have been inappropriate. $N$. meningitidis was the invasive pathogen identified in eight of the 11 (73\%) PICU admissions, and all deaths $2(0.2 \%)$. A further seven IBIs were identified, including five Pneumococcal infections, one E.coli infection, and one Group A Streptococcal infection. The combined number of all IBIs (including MD) was 26 of $1329(2 \cdot 0 \%)$. Table 3 summarises all cases of MD and IBI. 
There were 45 suspected contaminated blood culture results (supplementary material). None of these participants required PICU admission or inotropes, and all survived to discharge. A total of $346 / 1329(26 \%)$ did not undergo reference standard testing, of which two $(0 \cdot 6 \%)$ received parenteral antibiotics; one was subsequently diagnosed with a haematological malignancy, and the other was given a single dose in the ED before being discharged with a diagnosis of "Viral IIIness". In this cohort, 19 (6\%) had a single unplanned ED re-attendance within seven days, though none were subsequently admitted, treated with parenteral antibiotics, or diagnosed with MD or IBI.

The univariate analysis of individual clinical features is shown in Table 2, the clinical predictors that were deemed statistically significant $(p<0.20)$ were included in the multivariate analysis. Following multivariate analysis four independent risk factors for MD were identified. These were purpuric rash, shock (hypotension, prolonged capillary refill time of 4 seconds or more), reduced conscious level and limb pain $(p<0.01)$ for all.

All eight CPGs correctly identified all 19 cases of MD with identical sensitivities of 1.00 (95\% Cl 0.82-1.00) (Table 4). All eight CPGs correctly identified all 26 cases of IBI with identical sensitivities of $1.00(95 \% \mathrm{Cl} 0.87-1.00)$ (Table 5). The specificities varied more widely, with the NICE NG51 CPG demonstrating lowest specificity $(0.00 ; 95 \% \mathrm{Cl} 0.00-0.00)$ for identification of MD and for all IBI. This was followed by the NICE CG102 CPG, with specificity of $0.01(95 \% \mathrm{Cl} 0.01-0.02)$ for identification of MD and all IBI. All other CPGs analysed demonstrated significantly higher specificities $(p<0.0001)$. The CPGs with the highest specificities were the London CPG, with a specificity of $0.36(95 \% \mathrm{Cl} 0.34-0.39)$ for the identification of bot MD and IBI, and the Nottingham CPG with specificities of $0.34(95 \% \mathrm{CI}$ $0 \cdot 32-0 \cdot 37)$ and $0.35(95 \% \mathrm{CI} 0.32-0 \cdot 37)$ for the identification of MD and IBI respectively. The observed differences in specificity between the London CPG and the Nottingham CPG were not statistically significant $(p=1 \cdot 00)$. The performance of the CPGs can be seen in Tables 4 and 5. Performing the CPG validation using either single imputation, multiple imputation or 
exclusion of incomplete datasets had negligible effect on the results (Table available in the supplementary material). Irrespective of the approach to imputation all CPGs correctly identified all MD and IBI with the London and Nottingham CPGs consistently demonstrating the highest specificities with the NICE CPGs (NG51 and CG102) consistently significantly worse than the remaining six CPGs $(p<0.0001)$.

The most widely used CPG was the NICE CG102 29/37 (78\%) of sites followed by the NBL CPG 2/37 (5\%) of sites. Clinicians adhered to their departmental guidance in 607/1329 (46\%) of cases. This was similar if they used NICE CPGs (NG51 and CG102) 437/944 (46\%) or a tailored CPG (London CPG, Nottingham CPG, NBL CPG, Chester CPG, Glasgow CPG and Bristol CPG) 170/385 (44\%). Deviation from clinical practice guidelines resulted in fewer children receiving parenteral antibiotics 596/1329 (45\%) compared with any of the eight CPGs. These deviations from the CPGs also resulted in two children incorrectly discharged home with early MD. Both of whom were subsequently re-attended and were admitted to hospital. Both survived and did not require PICU. Clinician practice demonstrated a significantly $(p<0.0001)$ greater specificity than any CPGs for the diagnosis of MD or IBI $0.56(95 \% \mathrm{CI} 0.53$ to 0.59 ) for both (Tables 4 and 5). However clinician practice was less sensitive for the detection of $\mathrm{MD}$ and $\mathrm{IBI} 0.89(95 \% \mathrm{Cl} 0.67$ to 0.98 and $0.92(95 \% \mathrm{Cl} 0.75$ to 0.99$)$ respectively (Tables 4 and 5).

The two CPGs with the highest average costs per patient to the NHS were the NICE NG51, at $£ 660$ per patient (bootstrapped 95\% CI £620 to £706), and NICE CG102, at £655 per patient (bootstrapped $95 \% \mathrm{Cl} £ 615$ to $£ 701$ ). The more cost-minimising strategies were clinician practice, London CPG and Nottingham CPG with average costs per patient of $£ 426$ (bootstrapped 95\% Cl £382 to £475), £490 (bootstrapped 95\% Cl £448 to £538) and £499 (bootstrapped $95 \% \mathrm{Cl} £ 457$ to $£ 546$ ), respectively. The average costs per patient for all of the CPGs can be seen in Table 4. 


\section{Interpretation}

In this, the largest study of febrile children with non-blanching rashes to date, we enrolled participants from a range of hospital types and geographic regions over two winters to provide a true reflection of epidemiology, clinician practices, and performance accuracy of CPGs in the UK. Invasive bacterial infection rates were very low in our population, though the majority of these were due to invasive meningococcal disease, typically Serogroup B. Invasive meningococcal disease accounted for the most severe outcomes, including most of those who were admitted to a PICU, and both the children who died. All eight CPGs currently in use correctly identified all cases of MD and IBI, though the specificity varied more widely across guidelines, with national guidance performing significantly less favourably than other identified CPGs. We identified the optimally performing current CPGs, which provides a reasonable tradeoff between sensitivity and specificity in assisting clinician decision making.

The PiC study demonstrates that the risk of MD amongst febrile children attending the ED with non-blanching rashes in the UK is much lower than previously reported. Previous estimates had suggested that between $10 \%$ and $20 \%$ of children with fever and NBR have underlying MD $(7,9,11)$. However, the data informing these findings were mostly collected from inpatient populations prior to the introduction of the Meningococcal C vaccine (1999) and the Meningococcal B vaccine (2015) onto the UK vaccination schedule $(7,9,11-13)$. Successful vaccination programmes have led to a reduction in the number of cases of MD in the UK with the recent Meningococcal $B$ vaccination programme responsible for a $75 \%$ reduction in Meningococcal B infections amongst vaccinated children [12]. This is reflected in the PiC with $70 \%$ of the population having received the Meningococcal $\mathrm{B}$ vaccine and $73 \%$ having received the Meningococcal $\mathrm{C}$ vaccine and the proportion of participants with MD was just $1.4 \%$.

The eight CPGs included in the PiC can be broadly divided into three distinct strategies. The first, and most cautious, strategy is that all children with fever and NBR undergo investigation and treatment for MD including immediate administration of parenteral antibiotics i.e. NICE 
NG51. The second strategy involved performing blood tests on all children with fever and NBR and tailoring treatment based on a combination of clinical features and blood test results i.e. NICE CG120. The third, and least cautious, strategy involved tailored investigation and treatment with some children identified as suitable for discharge home without blood testing or parenteral antibiotics i.e. London CPG, Nottingham CPG, NBL CPG, Chester CPG, Glasgow CPG and Bristol CPG. In the PiC study it was the tailored approach that resulted in the best overall performance. The best performing CPG in the PiC study was the London and Nottingham CPGs with specificities of 0.36 and 0.35 respectively for the identification of IBI. The observed difference in performance between the Nottingham and London CPGs was not statistically significant $(p=1.00)$. The London and Nottingham CPGs were significantly more specific than either of the NICE CPGs $(p<0.0001)$.

Although the tailored approach advocated by six of the CPGs (London CPG, Nottingham CPG, NBL CPG, Chester CPG, Glasgow CPG and Bristol CPG) performed favourably when compared to the approaches suggested by NICE (NG51 and CG102) the specificities of the tailored CPGs varied significantly $(0.17$ to $0.37 \mathrm{p}<0.0001)$. The poorer performing CPGs such as the Chester and Bristol CPGs listed the greatest number of "Red Flag" features requiring treatment whereas the best performing CPGs such as the London and Nottingham CPGs listed the fewest number of "Red Flag" features. It appears that the greater the number of "Red Flag" features listed the lower the specificity of the guidance. All of the tailored CPGs included the presence of purpura and signs of shock as "Red Flags". None of the tailored CPGs included limb pain or reduced conscious level as "Red Flags" and data from this study suggest they should be considered as high risk clinical features. All of the tailored CPGs allowed for, well appearing children, with a mechanical cause for a petechial rash (not purpuric) to be discharged home.

Individual departments must now consider their own practice. Applying NICE CPG (CG102 and NG51) is likely to be safe although this approach involves the greatest use of parenteral 
antibiotics, the greatest number of painful procedures and the highest financial mean cost per patient ( $£ 655$ to $£ 660$ ). A tailored approach as exemplified by the London and Nottingham CPGs appears to be safe with reduced parenteral antibiotic use, reduced invasive procedures and a lower mean cost per patient (£490 to £499). Finally departments could allow for individual clinician practice. This approach would further reduce parenteral antibiotic used but would not alter the number of phlebotomy events performed and carries an increased risk of missing early MD. In $2017 / 18$, failure/delay diagnosis cost the NHS an average of $£ 227,667$ per case of litigation [21]. Individual clinician practice may lead to higher mean costs per patient than either NICE CPG or the use of a tailored approach due to the increased risk of missing early MD and subsequent litigation costs.

\section{Conclusion}

Due to successful vaccination programmes invasive meningococcal disease is now a rare cause of non-blanching rashes in children presenting with fever to the ED. Current UK NICE guidelines performed poorly when compared to locally produced guidelines with NICE guidance requiring a greater number of invasive procedures, greater use of parenteral antibiotics and greater financial cost without any demonstrable benefit.

\section{Strengths/Limitations}

The PiC study was the largest ever study of children with fever and NBR. It was performed prospectively across 37 UK sites and recruited 1334 children across two winters. It represents the best available evidence for estimating the risk of MD amongst children presenting to the ED with a fever and NBR. The PiC study also accurately reports the current performance of a range of CPGs. The main limitation to the PiC study was that there were very few cases of MD and such the confidence intervals for the sensitivity of each CPG are wide. The findings from $\mathrm{PiC}$ should therefore be interpreted with extreme caution in areas where the prevalence of MD is significantly higher than it is in the UK and where vaccines are not offered or uptake is low. An additional limitation is that even with a robust study design and prospective data 
collection some children with a fever and NBR will not have been included in the study. It is therefore possible that the reported proportion of children with MD in this cohort is an overestimation. 


\section{Declarations}

- Ethics approval: The Northern Ireland Research Ethics Committee (REC Reference 17/NI/0169) and the Belfast Health \& Social Care Trust Research Governance (Reference 16201MS-SW) approved the PiC protocol, including the embedded qualitative research.

- Conflicts of interests: Dr. Fairley is non-executive director, advisory board member and shareholder in Hibergene Diagnostics Ltd, Sandyford, Dublin, Republic of Ireland.

- Funding: This study was funded by the Public Health Agency of Northern Ireland (EAT/5313/16). The funder had no involvement in the design or conduct of the study.

- Authors contributions: Dr Waterfield, Dr Lyttle, Dr Roland, Dr Maney, Dr Fairley, Dr McKenna and Professor Shields conceived and designed the study. Dr Waterfield coordinated the running of the study including data management and site training. Dr Corr and Ms Patenall were involved with the conduct of the study including data collection. Dr Woolfall provided study design expertise and designed the approach to consent. Dr Lynn provided health economics expertise and supervised the cost assessment. $\mathrm{Dr}$ McFetridge and $\mathrm{Dr}$ Mitchell provided statistical expertise and performed the statistical analysis. All authors contributed to the writing of the manuscript.

- Acknowledgements; We thank all of the children and their families who participated in this study. We also thank all of the NHS sites and staff who participated in screening and enrolment and the independent members of the trial oversight committees. Details of site leads and research nurses can be found in the supplementary material.

- Data Sharing All of the individual participant data collected during this study will be available (including data dictionaries) on the Queen's University Belfast data repository. The full study protocol is available as an open access publication. 


\section{References}

1. Meningitis Research Foundation. Meningococcal Meningitis and Septicaemia [Internet]. 2016 [cited 2017 Oct 10]. Available from: https://www.meningitis.org/getmedia/cf777153$\underline{9427-4464-89 e 2-f b 58199174 b 6 / g p \text { booklet-UK-sept-16 }}$

2. Ó Maoldomhnaigh C, Drew RJ, Gavin P, Cafferkey M, Butler KM. Invasive meningococcal disease in children in Ireland, 2001-2011. Arch Dis Child [Internet]. 2016 Dec [cited 2017 Oct 10];101(12):1125-9. Available from: http://www.ncbi.nlm.nih.gov/pubmed/27566800 3. Corr M, Waterfield T, Shields M. Fifteen-minute consultation: Symptoms and signs of meningococcal disease. Arch Dis Child - Educ Pract [Internet]. 2019 Oct 16 [cited 2019 Oct 17];edpract-2019-317722. Available from:

https://ep.bmj.com/content/early/2019/10/16/archdischild-2019-317722

4. NICE. Meningitis (bacterial) and meningococcal septicaemia in under 16s: recognition, diagnosis and management | Guidance and guidelines | NICE. 2015 [cited 2017 Oct 10]; Available from: https://www.nice.org.uk/guidance/cg102

5. Lee D, Kim EJEJ, Kilgore PEPE, Kim SASA, Takahashi H, Ohnishi M, et al. Clinical evaluation of a loop-mediated isothermal amplification (LAMP) assay for rapid detection of Neisseria meningitidis in cerebrospinal fluid. PLoS One [Internet]. 2015 [cited 2017 Dec 4];10(4):e0122922. Available from:

http://www.plosone.org/article/fetchObject.action?uri=info:doi/10.1371/journal.pone.0122922 \&representation=PDF

6. Dunlop KA, Coyle P, Mitchell S, Fairley D, O'Neill H, Jackson P, et al. Molecular testing of respiratory swabs aids early recognition of meningococcal disease in children. Diagn Microbiol Infect Dis [Internet]. 2011;70(4):427-34. Available from: http://dx.doi.org/10.1016/i.diagmicrobio.2011.03.018

7. Brogan PA, Raffles A. The management of fever and petechiae: making sense of rash decisions. Arch Dis Child [Internet]. 2000;83(6):506-7. Available from: http://ovidsp.ovid.com/ovidweb.cgi?T=JS\&PAGE=reference \&D=med4\&NEWS=N\&AN=1108 
8. Mandl KD, Stack AM, Fleisher GR. Incidence of bacteremia in infants and children with fever and petechiae. J Pediatr [Internet]. 1997;131(3):398-404. Available from:

http://ovidsp.ovid.com/ovidweb.cgi?T=JS\&PAGE=reference \&D=med4\&NEWS=N\&AN=9329 $\underline{416}$

9. Wells LC, Smith JC, et al. The child with a non-blanching rash: How likely is meningococcal disease? Arch Dis Child [Internet]. 2001;85(3):218-22. Available from: http://ovidsp.ovid.com/ovidweb.cgi?T=JS\&PAGE=reference \&D=med4\&NEWS=N\&AN=1157 $\underline{104}$

10. Nielsen HE, Andersen EA, Andersen J, Bottiger B, Christiansen KM, Daugbjerg P, et al. Diagnostic assessment of haemorrhagic rash and fever. Arch Dis Child [Internet]. $2001 ; 85(2): 160-5$. Available from:

http://ovidsp.ovid.com/ovidweb.cgi?T=JS\&PAGE=reference \&D=med4\&NEWS=N\&AN=1146 $\underline{193}$

11. Riordan FAI, Jones L, Clark J. Validation of two algorithms for managing children with a nonblanching rash. Arch Dis Child. 2016;709-13.

12. Ladhani S, Andrews N, Parikh S et al. Vaccination of Infants with Meningococcal Group B Vaccine (4CMenB) in England. N Engl J Med 2020; 382:309-317. DOI:

10.1056/NEJMoa1901229.

13. Waterfield T, Lyttle MD, Fairley D, Mckenna J, Woolfall K, Lynn F, et al. The "Petechiae in children" ( $\mathrm{PiC})$ study: evaluating potential clinical decision rules for the management of feverish children with non-blanching rashes, including the role of point of care testing for Procalcitonin \&amp; Neisseria meningitidis DNA - a study protocol. BMC Pediatr [Internet]. 2018 Dec 30 [cited 2018 Sep 25];18(1):246. Available from:

http://www.ncbi.nlm.nih.gov/pubmed/30060751

14. CONNECT advisory group. Research without prior consent (deferred consent) in trials investigating the emergency treatment of critically ill children: CONNECT study guidance Version 2 updated July 2015 http://www.liv.ac.uk/psychologyhealthandsociety/research/connect/. 2015;(July). 
15. Lyttle MD, O'Sullivan R, Hartshorn S, Bevan C, Cleugh F, Maconochie I, et al. Pediatric Emergency Research in the UK and Ireland (PERUKI): developing a collaborative for multicentre research. Arch Dis Child [Internet]. 2014 Jun 1 [cited 2017 Nov 30];99(6):602-3. Available from: http://www.ncbi.nlm.nih.gov/pubmed/24615624

16. Waterfield T, Lyttle MD, Shields M, Fairley D, Roland D, McKenna J, et al. Parents' and clinicians' views on conducting paediatric diagnostic test accuracy studies without prior informed consent: qualitative insight from the Petechiae in Children study (PiC). Arch Dis Child [Internet]. 2019 Oct 1 [cited 2019 Oct 17];104(10):979-83. Available from: http://www.ncbi.nlm.nih.gov/pubmed/31175126

17. Harris PA, Taylor R, Thielke R, Payne J, Gonzalez N, Conde JG. Research electronic data capture (REDCap)_A metadata-driven methodology and workflow process for providing translational research informatics support. J Biomed Inform [Internet]. 2009 Apr [cited 2019 Oct 17];42(2):377-81. Available from:

http://www.ncbi.nlm.nih.gov/pubmed/18929686

18. Samuels M, Wieteska S. Advanced Paediatric Life Support: A Practical Approach to Emergencies, Sixth Edition. John Wiley \& Sons, Ltd. 2016 Feb.

19. Approved Costing Guidance Department of Health. (2018) NHS Reference Costs 201718. Department of Health: London, UK.

20. NHS Resolution. (2018) Freedom of Information Request 3539. NHS Resolution: London, UK. 
Tables

Table 1: Recruitment summary by site

\begin{tabular}{|c|c|c|c|c|c|}
\hline SITE NAME & $\begin{array}{l}\text { DATE } \\
\text { OPENED }\end{array}$ & $\begin{array}{l}\text { UPPER AGE } \\
\text { LIMIT }\end{array}$ & NUMBER & $\begin{array}{l}\text { NUMBER } \\
\text { OF MD }\end{array}$ & $\begin{array}{l}\text { CLINICAL PRACTICE } \\
\text { GUIDELINE USED }\end{array}$ \\
\hline ROYAL BELFAST HOSPITAL FOR SICK CHILDREN & 09/11/2017 & $14^{\text {th }}$ Birthday & 198 & 5 & NICE CG102 \\
\hline UNIVERSITY HOSPITALS OF MORECAMBE BAY & $24 / 05 / 2018$ & $16^{\text {th }}$ Birthday & 15 & 1 & NICE CG102 \\
\hline SALISBURY DISTRICT HOSPITAL & 05/07/2018 & $18^{\text {th }}$ Birthday & 23 & 0 & NICE CG102 \\
\hline NOTTINGHAM CHILDREN'S HOSPITAL & $28 / 08 / 2018$ & $16^{\text {th }}$ Birthday & 46 & 0 & Nottingham CPG \\
\hline SOUTHPORT DISTRICT GENERAL HOSPITAL & $28 / 09 / 2018$ & $16^{\text {th }}$ Birthday & 26 & 0 & NICE CG102 \\
\hline NEW CROSS HOSPITAL WOLVERHAMPTON & $01 / 10 / 2018$ & $18^{\text {th }}$ Birthday & 26 & 0 & NICE CG102 \\
\hline LEIGHTON HOSPITAL & $01 / 10 / 2018$ & $16^{\text {th }}$ Birthday & 24 & 0 & NICE CG102 \\
\hline LEICESTER ROYAL INFIRMARY & 04/10/2018 & $16^{\text {th }}$ Birthday & 59 & 1 & NICE CG102 \\
\hline ROYAL LONDON HOSPITAL & $08 / 10 / 2018$ & $18^{\text {th }}$ Birthday & 37 & 0 & London CPG \\
\hline COUNTESS OF CHESTER HOSPITAL & $11 / 10 / 2018$ & $16^{\text {th }}$ Birthday & 58 & 1 & Chester CPG \\
\hline YEOVIL DISTRICT HOSPITAL & $15 / 10 / 2018$ & $18^{\text {th }}$ Birthday & 13 & 0 & NICE CG102 \\
\hline WARRINGTON HOSPITAL & $15 / 10 / 2018$ & $18^{\text {th }}$ Birthday & 20 & 1 & NICE CG102 \\
\hline AIREDALE GENERAL HOSPITAL & $17 / 10 / 2018$ & $18^{\text {th }}$ Birthday & 14 & 0 & NICE CG102 \\
\hline UNIVERSITY HOSPITAL LEWISHAM & $07 / 11 / 2018$ & $16^{\text {th }}$ Birthday & 50 & 0 & NICE CG102 \\
\hline BRISTOL ROYAL HOSPITAL FOR CHILDREN & $08 / 11 / 2018$ & $16^{\text {th }}$ Birthday & 144 & 0 & Bristol CPG \\
\hline WEXHAM PARK HOSPITAL & $12 / 11 / 2018$ & $18^{\text {th }}$ Birthday & 12 & 0 & NICE CG102 \\
\hline ARROWE PARK HOSPITAL & $13 / 11 / 2018$ & $16^{\text {th }}$ Birthday & 28 & 0 & NICE CG102 \\
\hline BRADFORD ROYAL INFIRMARY & $15 / 11 / 2018$ & $16^{\text {th }}$ Birthday & 26 & 0 & NICE CG102 \\
\hline ROYAL PRESTON HOSPITAL & $16 / 11 / 2018$ & $16^{\text {th }}$ Birthday & 12 & 0 & NICE CG102 \\
\hline QUEEN'S HOSPITAL ROMFORD & $19 / 11 / 2018$ & $16^{\text {th }}$ Birthday & 13 & 1 & NICE CG102 \\
\hline ST RICHARDS HOSPITAL CHICHESTER & $27 / 11 / 2018$ & $18^{\text {th }}$ Birthday & 47 & 0 & NICE CG102 \\
\hline ALDER HEY CHILDREN'S HOSPITAL & $28 / 11 / 2018$ & $16^{\text {th }}$ Birthday & 91 & 3 & NBL CPG \\
\hline BIRMINGHAM CHILDREN'S HOSPITAL & $28 / 11 / 2018$ & $16^{\text {th }}$ Birthday & 67 & 4 & NBL CPG \\
\hline HUDDERSFIELD ROYAL INFIRMARY & $21 / 12 / 2018$ & $16^{\text {th }}$ Birthday & 11 & 0 & NICE CG102 \\
\hline ROYAL DERBY HOSPITAL & $27 / 12 / 2018$ & $18^{\text {th }}$ Birthday & 33 & 0 & NBL CPG \\
\hline EPSOM HOSPITAL & 02/01/2019 & $18^{\text {th }}$ Birthday & 36 & 0 & NICE CG102 \\
\hline WORTHING HOSPITAL & 03/01/2019 & $18^{\text {th }}$ Birthday & 15 & 0 & NICE CG102 \\
\hline UNIVERSITY HOSPITAL SOUTHAMPTON & 07/01/2019 & $18^{\text {th }}$ Birthday & 14 & 0 & NICE CG102 \\
\hline STOKE MANDEVILLE HOSPITAL & $11 / 01 / 2019$ & $16^{\text {th }}$ Birthday & 11 & 0 & NICE CG102 \\
\hline SHEFFIELD CHILDREN'S HOSPITAL & $13 / 01 / 2019$ & $16^{\text {th }}$ Birthday & 28 & 0 & NICE CG102 \\
\hline DONCASTER ROYAL INFIRMARY & $21 / 01 / 2019$ & $16^{\text {th }}$ Birthday & 20 & 1 & NICE CG102 \\
\hline QUEEN'S HOSPITAL BURTON & $29 / 01 / 2019$ & $17^{\text {th }}$ Birthday & 21 & 0 & NICE CG102 \\
\hline TAYSIDE CHILDREN'S HOSPITAL & 09/02/2019 & $16^{\text {th }}$ Birthday & 13 & 0 & NICE NG51 \\
\hline UNIVERSITY HOSPITAL CROSSHOUSE & 02/03/2019 & $16^{\text {th }}$ Birthday & 16 & 0 & NICE CG102 \\
\hline MUSGROVE PARK HOSPITAL & $11 / 03 / 2019$ & $16^{\text {th }}$ Birthday & 1 & 0 & NICE CG102 \\
\hline PINDERFIELDS HOSPITAL & 20/03/2019 & $18^{\text {th }}$ Birthday & 21 & 1 & NICE CG102 \\
\hline ROYAL HOSPITAL FOR CHILDREN G & $06 / 04 / 2019$ & $16^{\text {th }}$ Birthday & 40 & 0 & Glasgow CPG \\
\hline
\end{tabular}


Table 2: Univariate analysis of predictors (Chi-squared for categorical variables, Mann-Whitney $U$ for continuous variables). Number and (\%) with feature shown for categorical variables and median for continuous variables*.

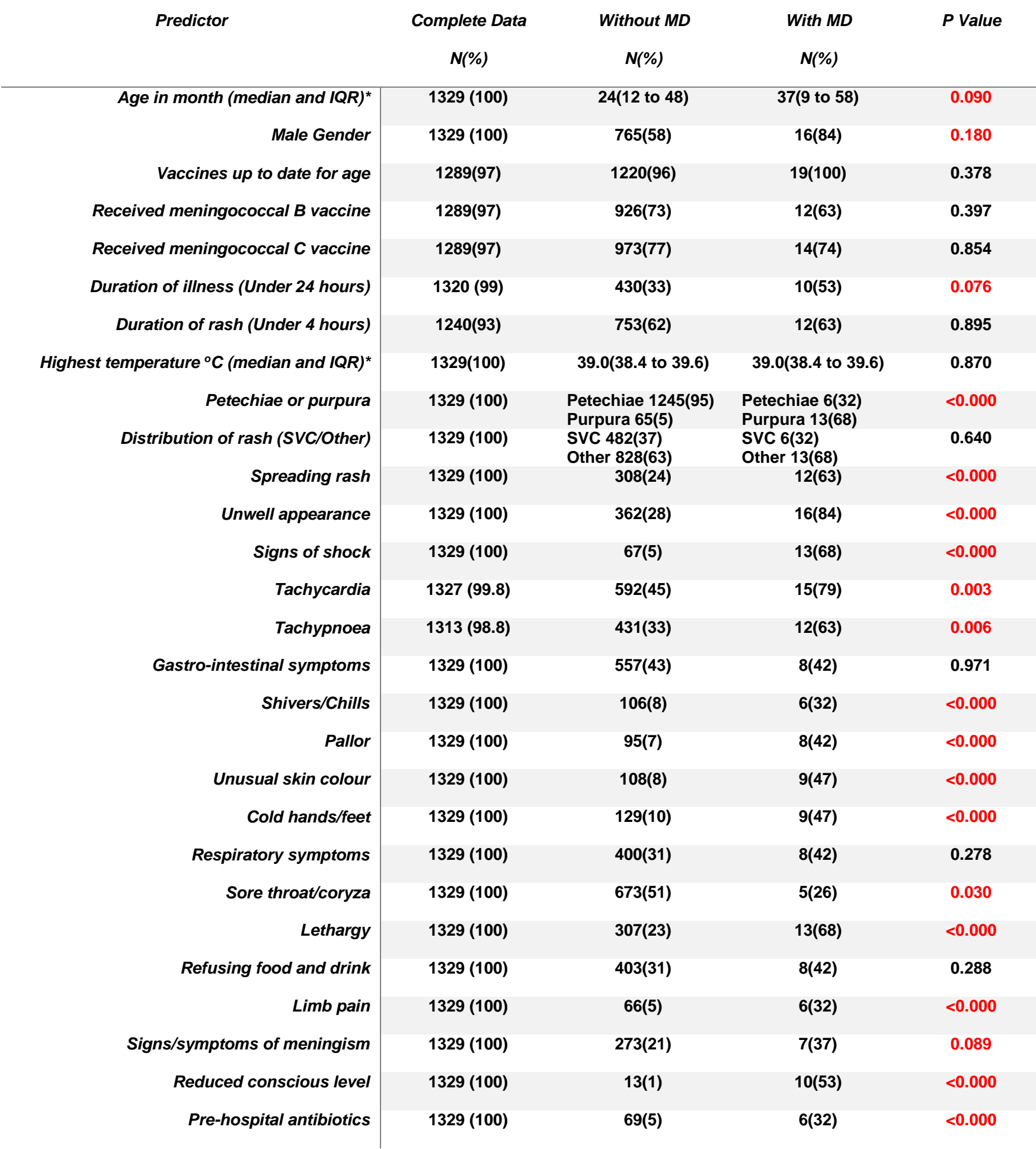

$\mathrm{MD}=$ meningococcal disease. Meningism includes Brudzinski's sign, Kernig's sign, bulging fontanelle, irritability, photophobia, neck stiffness and headache. Shock includes clinician diagnosed shock, prolonged capillary refill time of 4 seconds or more and hypotension. Gastro-intestinal symptoms included abdominal pain, abdominal distension, diarrhoea and nausea/vomiting. 
Table 3: All invasive bacterial infections $(n=26)$ including all meningococcal disease $(n=19)$ PICU=Paediatric Intensive Care

\begin{tabular}{|c|c|c|c|c|c|c|c|}
\hline Diagnosis & Blood Culture & Blood qPCR & CSF Culture/qPCR & $\begin{array}{l}\text { PICU } \\
\text { Admission }\end{array}$ & Survival & $\begin{array}{l}\text { Doses of } \\
\text { Meningococcal } \\
\text { B Vaccine }\end{array}$ & $\begin{array}{l}\text { Doses of } \\
\text { Meningococcal C } \\
\text { Vaccine }\end{array}$ \\
\hline S. pneumoniae & S. pneumoniae & Negative & Not Tested & No & Yes & Unknown & Unknown \\
\hline S. pneumoniae & S. pneumoniae & Negative & Not Tested & No & Yes & Unknown & Unknown \\
\hline S. pneumoniae & Negative & S. pneumoniae & Not Tested & No & Yes & 0 & 3 \\
\hline S. pneumoniae & Negative & S. pneumoniae & Not Tested & No & Yes & 0 & 3 \\
\hline S. pneumoniae & Negative & S. pneumoniae & Not Tested & No & Yes & 3 & 1 \\
\hline S. pyogenes & S. pyogenes & Not Tested & Not Tested & Yes & Yes & 0 & 3 \\
\hline E.coli & E.coli & Negative & Negative & No & Yes & 2 & 0 \\
\hline N. meningitidis $\mathrm{B}$ & Negative & N. meningitidis B & Not Tested & No & Yes & 3 & 2 \\
\hline N. meningitidis $\mathrm{B}$ & Not Tested & N. meningitidis B & Not Tested & No & Yes & 0 & 3 \\
\hline N. meningitidis $\mathrm{B}$ & Negative & N. meningitidis B & Negative & No & Yes & 0 & 3 \\
\hline N. meningitidis B & Negative & N. meningitidis B & Not Tested & No & Yes & 0 & 3 \\
\hline N. meningitidis B & N. meningitidis B & N. meningitidis B & Negative & Yes & Yes & 0 & 3 \\
\hline N. meningitidis $\mathrm{B}$ & Negative & N. meningitidis B & Not Tested & No & Yes & 0 & 3 \\
\hline N. meningitidis $\mathrm{B}$ & N. meningitidis B & N. meningitidis B & Not Tested & No & Yes & 1 & 0 \\
\hline N. meningitidis $\mathrm{B}$ & N. meningitidis B & N. meningitidis B & Not Tested & No & Yes & 0 & 3 \\
\hline N. meningitidis $\mathrm{B}$ & Negative & N. meningitidis B & Not Tested & Yes & Yes & 3 & 2 \\
\hline N. meningitidis $\mathrm{B}$ & Negative & N. meningitidis B & Not Tested & No & Yes & 1 & 0 \\
\hline N. meningitidis B & N. meningitidis B & N. meningitidis B & Negative & Yes & Yes & 2 & 0 \\
\hline N. meningitidis $\mathrm{B}$ & Negative & N. meningitidis B & Not Tested & Yes & Yes & 3 & 2 \\
\hline N. meningitidis $\mathrm{B}$ & N. meningitidis $\mathrm{B}$ & N. meningitidis B & Not Tested & Yes & No & 0 & 3 \\
\hline N. meningitidis B & Negative & N. meningitidis B & Not Tested & No & Yes & 3 & 2 \\
\hline N. meningitidis B & N. meningitidis B & N. meningitidis B & Not Tested & No & Yes & 3 & 2 \\
\hline N. meningitidis $\mathrm{B}$ & N. meningitidis $\mathrm{B}$ & N. meningitidis B & Not Tested & Yes & No & 1 & 0 \\
\hline N. meningitidis B & Negative & Negative & N. meningitidis $\mathrm{B}$ & No & Yes & 3 & 2 \\
\hline N. meningitidis C & Negative & N. meningitidis C & Not Tested & Yes & Yes & 2 & 0 \\
\hline N. meningitidis W & N. meningitidis W & N. meningitidis W & Negative & Yes & Yes & 2 & 0 \\
\hline
\end{tabular}


Table 4: Diagnostic performance of CPGs at identifying meningococcal disease (single imputation)

\begin{tabular}{|c|c|c|c|c|c|c|c|c|c|}
\hline \multirow{2}{*}{$\begin{array}{l}\text { Clinical } \\
\text { Practice } \\
\text { Guideline }\end{array}$} & \multirow{2}{*}{$\begin{array}{c}\text { Number of } \\
\text { Blood Tests } \\
\mathrm{n}(\%)\end{array}$} & \multirow[t]{2}{*}{ Outcome } & \multicolumn{2}{|c|}{$\begin{array}{c}\text { Meningococcal Disease } \\
(n=19)\end{array}$} & \multirow{2}{*}{$\begin{array}{l}\text { Sensitivity } \\
(95 \% \mathrm{Cl})\end{array}$} & \multirow{2}{*}{$\begin{array}{l}\text { Specificity } \\
\text { (95\% Cl) }\end{array}$} & \multirow{2}{*}{$\begin{array}{c}\text { Positive } \\
\text { Predictive Value } \\
\text { (95\%Cl) }\end{array}$} & \multirow{2}{*}{$\begin{array}{c}\text { Negative } \\
\text { Predictive Value } \\
(95 \% \mathrm{Cl})\end{array}$} & \multirow{2}{*}{$\begin{array}{l}\text { Mean Cost per Patient } \\
\text { (Bootstrapped } 95 \% \mathrm{Cl} \text { ) }\end{array}$} \\
\hline & & & Present & Absent & & & & & \\
\hline \multirow{2}{*}{$\begin{array}{l}\text { Clinician } \\
\text { Practice }\end{array}$} & \multirow{2}{*}{$\begin{array}{l}1137 \\
(86)\end{array}$} & Treat & 17 & 579 & \multirow{2}{*}{$\begin{array}{c}0.89 \\
(0.67 \text { to } 0.99) \\
\end{array}$} & \multirow{2}{*}{$\begin{array}{c}0.56 \\
(0.53 \text { to } 0.59) \\
\end{array}$} & \multirow{2}{*}{$\begin{array}{c}0.03 \\
(0.02 \text { to } 0.05) \\
\end{array}$} & \multirow{2}{*}{$\begin{array}{c}1.00 \\
\text { (0.99 to } 1.00)\end{array}$} & \multirow{2}{*}{$\begin{array}{c}£ 425.95 \\
(£ 382.06 \text { to } 4474.65) \\
\end{array}$} \\
\hline & & Do Not Treat & 2 & 731 & & & & & \\
\hline \multirow{2}{*}{ London } & \multirow{2}{*}{$\begin{array}{l}997 \\
(75) \\
\end{array}$} & Treat & 19 & 835 & \multirow{2}{*}{$\begin{array}{c}1.00 \\
(0.82 \text { to } 1.00)\end{array}$} & \multirow{2}{*}{$\begin{array}{c}0.36 \\
(0.34 \text { to } 0.39)\end{array}$} & \multirow{2}{*}{$\begin{array}{c}0.02 \\
(0.01 \text { to } 0.03) \\
\end{array}$} & \multirow{2}{*}{$\begin{array}{c}1.00 \\
(0.99 \text { to } 1.00)\end{array}$} & \multirow{2}{*}{$\begin{array}{c}£ 490.29 \\
\text { (£447.60 to £537.98) }\end{array}$} \\
\hline & & Do Not Treat & 0 & 475 & & & & & \\
\hline \multirow{2}{*}{ Nottingham } & \multirow{2}{*}{$\begin{array}{c}1030 \\
(78) \\
\end{array}$} & Treat & 19 & 859 & \multirow{2}{*}{$\begin{array}{c}1.00 \\
(0.82 \text { to } 1.00)\end{array}$} & \multirow{2}{*}{$\begin{array}{c}0.34 \\
(0.32 \text { to } 0.37) \\
\end{array}$} & \multirow{2}{*}{$\begin{array}{c}0.02 \\
(0.01 \text { to } 0.03) \\
\end{array}$} & \multirow{2}{*}{$\begin{array}{c}1.00 \\
(0.99 \text { to } 1.00)\end{array}$} & \multirow{2}{*}{$\begin{array}{c}£ 498.88 \\
\text { (£456.56 to £546.21) } \\
\end{array}$} \\
\hline & & Do Not Treat & 0 & 451 & & & & & \\
\hline \multirow{2}{*}{ NBL } & \multirow{2}{*}{$\begin{array}{l}1019 \\
(77) \\
\end{array}$} & Treat & 19 & 893 & \multirow{2}{*}{$\begin{array}{c}1.00 \\
(0.82 \text { to } 1.00) \\
\end{array}$} & \multirow{2}{*}{$\begin{array}{c}0.32 \\
(0.29 \text { to } 0.34) \\
\end{array}$} & 0.02 & 1.00 & $£ 511.06$ \\
\hline & & Do Not Treat & 0 & 417 & & & (0.01 to 0.03$)$ & (0.99 to 1.00$)$ & (£468.38 to £558.76) \\
\hline Glasanw & 1030 & Treat & 19 & 897 & 1.00 & 0.32 & 0.02 & 1.00 & $£ 512.49$ \\
\hline Miasogur & (78) & Do Not Treat & 0 & 413 & (0.82 to 1.00$)$ & (0.29 to 0.34$)$ & (0.01 to 0.03$)$ & (0.99 to 1.00$)$ & (£469.79 to £558.76) \\
\hline Chester & 1087 & Treat & 19 & 965 & 1.00 & 0.26 & 0.02 & 1.00 & $£ 536.85$ \\
\hline (1) & (82) & Do Not Treat & 0 & 345 & (0.82 to 1.00$)$ & (0.24 to 0.29$)$ & (0.01 to 0.03 ) & (0.99 to 1.00$)$ & (£494.17 to £582.76) \\
\hline Bristol & 1169 & Treat & 19 & 1092 & 1.00 & 0.17 & 0.02 & 1.00 & $£ 582.33$ \\
\hline 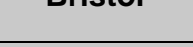 & (88) & Do Not Treat & 0 & 218 & (0.82 to 1.00$)$ & $(0.15$ to 0.19$)$ & (0.01 to 0.03$)$ & (0.98 to 1.00$)$ & (£540.01 to £629.00) \\
\hline NICF CG102 & 1329 & Treat & 19 & 1295 & 1.00 & 0.01 & 0.0 & 1.0 & $£ 655.04$ \\
\hline The & (100) & Do Not Treat & 0 & 15 & (0.82 to 1.00$)$ & (0.01 to 0.02$)$ & (0.01 to 0.02$)$ & $(0.78 \mathrm{t}$ & (£614.87 to £700.60) \\
\hline NICE NG51 & 1329 & Treat & 19 & 1310 & 1.00 & 0 & 0.01 & $N / A$ & $£ 660.41$ \\
\hline & (100) & Do Not Treat & 0 & 0 & (0.82 to 1.00$)$ & (0.00 to 0.00$)$ & (0.01 to 0.02$)$ & & (£620.24 to £705.61) \\
\hline
\end{tabular}


Table 5: Diagnostic performance of CPGs at identifying all invasive bacterial infection (single imputation)

\begin{tabular}{|c|c|c|c|c|c|c|c|}
\hline \multirow{2}{*}{$\begin{array}{l}\text { Clinical } \\
\text { Practice } \\
\text { Guideline }\end{array}$} & \multirow[t]{2}{*}{ Outcome } & \multicolumn{2}{|c|}{$\begin{array}{l}\text { Invasive Bacterial } \\
\text { Infection }(\mathrm{n}=26)\end{array}$} & \multirow{2}{*}{$\begin{array}{l}\text { Sensitivity } \\
(95 \% \mathrm{Cl})\end{array}$} & \multirow{2}{*}{$\begin{array}{l}\text { Specificity } \\
(95 \% \mathrm{Cl})\end{array}$} & \multirow{2}{*}{$\begin{array}{c}\text { Positive Predictive } \\
\text { Value } \\
(95 \% \mathrm{Cl})\end{array}$} & \multirow{2}{*}{$\begin{array}{c}\text { Negative Predictive } \\
\text { Value } \\
(95 \% \mathrm{Cl})\end{array}$} \\
\hline & & Present & Absent & & & & \\
\hline \multirow{2}{*}{$\begin{array}{l}\text { Clinician } \\
\text { Practice }\end{array}$} & Treat & 24 & 572 & \multirow{2}{*}{$\begin{array}{c}0.92 \\
(0.75 \text { to } 0.99)\end{array}$} & \multirow{2}{*}{$\begin{array}{c}0.56 \\
(0.53 \text { to } 0.59)\end{array}$} & \multirow{2}{*}{$\begin{array}{c}0.04 \\
(0.03 \text { to } 0.06)\end{array}$} & \multirow{2}{*}{$\begin{array}{c}1.00 \\
(0.99 \text { to } 1.00)\end{array}$} \\
\hline & Do Not Treat & 2 & 731 & & & & \\
\hline \multirow{2}{*}{ London } & Treat & 26 & 828 & \multirow{2}{*}{$\begin{array}{c}1.00 \\
(0.87 \text { to } 1.00)\end{array}$} & \multirow{2}{*}{$\begin{array}{c}0.36 \\
(0.34 \text { to } 0.39)\end{array}$} & \multirow{2}{*}{$\begin{array}{c}0.03 \\
(0.02 \text { to } 0.04)\end{array}$} & \multirow{2}{*}{$\begin{array}{c}1.00 \\
(0.99 \text { to } 1.00)\end{array}$} \\
\hline & Do Not Treat & 0 & 475 & & & & \\
\hline \multirow{2}{*}{ Nottingham } & Treat & 26 & 852 & \multirow{2}{*}{$\begin{array}{c}1.00 \\
(0.87 \text { to } 1.00)\end{array}$} & \multirow{2}{*}{$\begin{array}{c}0.35 \\
(0.32 \text { to } 0.37)\end{array}$} & \multirow{2}{*}{$\begin{array}{c}0.03 \\
(0.02 \text { to } 0.04)\end{array}$} & \multirow{2}{*}{$\begin{array}{c}1.00 \\
(0.99 \text { to } 1.00)\end{array}$} \\
\hline & Do Not Treat & 0 & 451 & & & & \\
\hline \multirow{2}{*}{ NBL } & Treat & 26 & 886 & \multirow{2}{*}{$\begin{array}{c}1.00 \\
(0.87 \text { to } 1.00)\end{array}$} & \multirow{2}{*}{$\begin{array}{c}0.32 \\
(0.29 \text { to } 0.35)\end{array}$} & \multirow{2}{*}{$\begin{array}{c}0.03 \\
(0.02 \text { to } 0.04)\end{array}$} & \multirow{2}{*}{$\begin{array}{c}1.00 \\
(0.99 \text { to } 1.00)\end{array}$} \\
\hline & Do Not Treat & 0 & 417 & & & & \\
\hline \multirow{2}{*}{ Glasgow } & Treat & 26 & 890 & \multirow{2}{*}{$\begin{array}{c}1.00 \\
(0.87 \text { to } 1.00) \\
\end{array}$} & \multirow{2}{*}{$\begin{array}{c}0.32 \\
(0.29 \text { to } 0.34)\end{array}$} & \multirow{2}{*}{$\begin{array}{c}0.03 \\
(0.02 \text { to } 0.04)\end{array}$} & \multirow{2}{*}{$\begin{array}{c}1.00 \\
(0.99 \text { to } 1.00)\end{array}$} \\
\hline & Do Not Treat & 0 & 413 & & & & \\
\hline \multirow{2}{*}{ Chester } & Treat & 26 & 958 & \multirow{2}{*}{$\begin{array}{c}1.00 \\
(0.87 \text { to } 1.00)\end{array}$} & \multirow{2}{*}{$\begin{array}{c}0.26 \\
(0.24 \text { to } 0.29)\end{array}$} & & \\
\hline & Do Not Treat & 0 & 345 & & & (0.02 to 0.04$)$ & (0.99 to 1.00$)$ \\
\hline & Treat & 26 & 1085 & 1.00 & 0.17 & 0.02 & 1.00 \\
\hline Bristol & Do Not Treat & 0 & 218 & $(0.87$ to 1.00$)$ & (0.15 to 0.19$)$ & $(0.02$ to 0.03$)$ & (0.98 to 1.00$)$ \\
\hline & Treat & 26 & 1288 & 1.00 & 0.01 & 0.02 & 1.00 \\
\hline NICE CG102 & Do Not Treat & 0 & 15 & (0.87 to 1.00$)$ & (0.01 to 0.02$)$ & $(0.01$ to 0.03$)$ & (0.78 to 1.00$)$ \\
\hline & Treat & 26 & 1303 & 1.00 & & 0.02 & \\
\hline NICE NG51 & Do Not Treat & 0 & 0 & $(0.87$ to 1.00$)$ & $(0.00$ to 0.00$)$ & (0.01 to 0.03$)$ & $\mathrm{N} / \mathrm{A}$ \\
\hline
\end{tabular}




\section{Research in context}

\section{Evidence before this study}

Historically it has been reported that between $10 \%$ and $20 \%$ of children with fever and a non-blanching rash will have an underlying meningococcal infection. Due to this reported high risk of meningococcal disease many clinical practice guidelines advocate an aggressive approach to investigation and treatment of any child with a history of fever and a non-blanching rash. This leads to many children undergoing painful procedures and receiving parenteral antibiotics. Unfortunately the studies on which these guidelines are based were conducted prior to the introduction of meningococcal vaccinations, on small populations of inpatient children using convenience sampling or retrospective data collection. The vast majority of clinical practice guidelines currently in use in the UK have never been validated and none have been validated in a vaccinated population.

\section{Added value of this study}

This study is the largest study of fever of non-blanching rash conducted to date and the first to be conducted in a vaccinated population. This study has shown that, currently in the UK, meningococcal disease is a rare cause of fever and non-blanching rash, accounting for just $1.4 \%$ of cases and that in this population the guidelines produced by National Institute for Health and Care Excellence perform poorly.

\section{Implications of all the available evidence}

This study supports a change, in the UK, from current NICE guidance to a more tailored approach. Changing to a tailored approach as exemplified by the London CPG would have resulted in 332 fewer children requiring blood tests, 475 fewer children requiring parenteral antibiotics and cost saving per patient of $£ 178$ (compared to NICE NG51).

Figure 1: Study Flow Diagram 